\begin{tabular}{|l|l|l|l|l|l|}
\hline Revista Clío América & ISSN: 1909-941X & Vol. 10 & No. 20 & Julio - Diciembre de 2016 & 139 - 159 \\
\hline \multicolumn{6}{c|}{ DOI: http://dx.doi.org/10.21676/23897848.1873 } \\
\hline
\end{tabular}

\title{
Estudio de la región Michoacana de Zamora como polo de competitividad internacional agrícola
}

\author{
Study of the Michoacan province of Zamora as a pole of international competitiveness in \\ agriculture
}

América I. Zamora-Torres

PhD., Profesora Investigadora del Instituto de Investigaciones Económicas y Empresariales de la Universidad Michoacana de San Nicolás de Hidalgo, México. Email: americazt@hotmail.com

Estefanía Riveros-Figueroa Licenciada en Relaciones Comerciales Internacionales por la Universidad Latina de América, México. Email:erf2292@gmail.com

Tipología:

Artículo de Investigación Científica y Tecnológica

Fecha de Recibido: Julio 05 de 2016

Fecha de Aceptación: Septiembre 23 de 2016

Para citar este artículo:

Zamora, T. A., \& Riveros, F. E. (2016). Estudio de la región Michoacana de Zamora como polo de competitividad internacional agrícola, Clío América, 10 (20), pp. 139 - 159
Resumen: El valle de Zamora, ubicado en el estado de Michoacán en México, es una localidad reconocida a nivel mundial por su producción agrícola de alto nivel, específicamente en lo referido a su exportación de fresa. El presente trabajo analiza el impacto de la productividad agrícola, los recursos productivos, los programas gubernamentales y la relación entre empresas sobre la competitividad internacional zamorana. Dando cuenta de que los factores productivos considerados por la teoría marxista y de intensidad de los factores productivos de Heckscher-0hlin que refieren a: Tierra, capital y trabajo, si bien son la base desde la cual se parte para generar productividad, es notorio que en el sistema económico actual, requieren de factores intangibles complementarios.

Palabras clave: desarrollo regional, competitividad internacional, sector agrícola.

JEL: F0, F10, 013, 018 y 017.

Abstract: The Zamora Valley is located in Michoacan state, Mexico, it is worldwide recognized locality because of its high performance agricultural production, specialy concerning strawberry export. The current study analyzed the agricultural productivity impact, productive resources, government programs and the company relationship on the Zamora's international competitiveness. Taking in account that the productive factors, considered in the Marxist theory and the intensity of the Heckscher-Ohlin's productive factors, which refer to land, capital and work, whereas they are the base from which productivity is generated, it is highlighting that in the current economic system, they need complementary intangible factors.

Keywords: regional development, agricultural sector, international competitiveness. 


\section{Introducción}

En el mundo globalizado actual, las estrategias de competitividad destacan en la participación dentro de la dinámica global de comercio internacional. En función de los cambios experimentados en el sistema internacional toda vez que la globalización fue una realidad, los empresarios de cada país vieron como un reto, a la vez que una oportunidad, la posibilidad de expandir su mercado a consumidores de otras partes del mundo.

Ello conllevó a nuevas prácticas de gestión empresarial, entre las que se encontraba como un imperativo el contar con un departamento de comercio exterior al interior de algunas empresas, así como una continua actualización en las nuevas políticas de homologación legal en términos de comercio internacional.

El término en boga lo constituía lo "global" entendiendo que el mundo cobraba notoriedad como un todo, siendo lo homogéneo lo importante aunque paralelamente, surgían otros problemas de indole ética y política, tales como la erosión de la soberanía del Estado, el institucionalismo y las nuevas formas de gobierno mundial, la pérdida de identidad y la extinción de las tradiciones, entre otros.

Sin embargo, en los últimos años el concepto de lo global ha evolucionado hacia un término más incluyente, donde no sólo se habla de una cadena de valor que involucra la internacionalización de las empresas y donde la teoría de Wallerstein, los polos de poder y el centro y la periferia han cambiado hacia un mundo interdependiente, donde se da cabida a lo local, como pieza clave y estratégica, teniendo ejemplos destacados como son la creación de clústers, corredores industriales, proveedores locales que generan alianzas estratégicas, etc., y que reconocen que el desarrollo regional y local es parte crucial para el desarrollo global.

Michoacán ha descollado en el plano internacional como un referente en producción agrícola, donde su producto estrella ha girado en torno al aguacate, sin embargo, un cultivo igual de atrayente y aun ciertamente marginado dentro de la investigación agrícola es la fresa.
"Michoacán y Baja California producen aproximadamente el $87 \%$ del total de fresa en México." (CONAFRE \& Comité de la Agroindustria y Productores , 2011, pág. 3) y desde hace poco más de una década, figuran entre los estados de la República Mexicana que han sido tradicionalmente cultivadores de fresa; daban cuenta de ello Barrera y Sánchez (2003) de la fundación Produce Michoacán A.C., al mencionar que la fresa a pesar de que se cultiva en cerca de 11 entidades, son tres las principales que han destacado: “Michoacán, Guanajuato y Baja California, pues contribuyen con el $95 \%$ tanto de la superficie sembrada y de la producción a nivel nacional" (pág. 7). Todavía en el año 2011, las mismas entidades figuraban en la lista de productores, agregándose además los estados de Jalisco y Estado de México, sin embargo, los ya mencionados (Michoacán, Guanajuato y Baja California) siguen ostentando los primeros lugares.

Asimismo, cabe resaltar que, de dicho cultivo, "Los principales usos son fresa fresca, fresa azucarada, IQF (fresa congelada individualmente sin azúcar), puré con y sin azúcar, pure-pack (fresa rebanada) y puré con azúcar" (Barrera \& Sánchez, 2003, pág. 7). De hecho, de acuerdo con la Unión Agrícola Regional de Productores de Fresa y Hortalizas del Valle de Zamora (2009) los datos clave de la industria fresera resaltan que: "La fruta fresca participa con un $86 \%$ de la participación de mercados y ha crecido un $6.3 \%$ de 2006 a 2008. La fruta envasada y enlatada creció un $6.7 \%$ y la fruta deshidratada y congelada crecieron $16.8 \%$ y $11.7 \%$ respectivamente de 2006 a 2008." (pág. 5).

La fresa es una de las frutillas más conocidas a nivel mundial y está presente en diversos productos y en el gusto del consumidor final. Al respecto, Michoacán específicamente a través de la región del valle de Zamora, se constituye dentro de los principales productores de esta fruta a nivel nacional al aportar poco más del $50 \%$ de la producción nacional, la cual debido a su calidad tiene como destino su exportación al mercado estadounidense.

Por lo tanto, el tema que aborda el presente trabajo es la región de Zamora con el objetivo de identificar cómo impactan las variables de recursos productivos, productividad agrícola, actuación del gobierno y 
relación entre las empresas, sobre la competitividad de Zamora en el plano internacional.

De ahí que en el primer apartado se fundamente el problema observado, para posteriormente brindar un panorama de sus antecedentes y a la par de revisar la literatura académica, establecer las variables y la metodología a emplearse con motivo del análisis de la información. Por último, se vierten las conclusiones obtenidas y se anexan las fuentes consultadas.

\section{Fundamentación del Problema}

El estado de Michoacán de Ocampo constituye en términos de producción agrícola nacional un referente que lo ha mantenido dentro de las primeras cinco entidades productoras a nivel República Mexicana. En el año 2010, Michoacán ocupó el lugar número 25 a nivel México según el Índice de Competitividad Estatal. (IMCO, 2010) Tan sólo la región de Zamora constituye poco más de la mitad de la producción de fresa a nivel nacional (SIAP, 2016).

Bajo dicha tesitura, el presente artículo se centra en la localidad de Zamora, municipio ubicado dentro del estado de Michoacán, mismo que es una entidad federativa ubicada en el occidente de México cuya ubicación geográfica lo coloca en términos logísticos en una posición privilegiada, destacando como ya se mencionaba, su producción agrícola. Dicha región michoacana constituye un enclave de primer lugar nacional para el cultivo de fresa, zarzamora, mango y demás frutas que cuentan con una calidad de exportación de talla mundial, de donde surge la importancia de estudiar las condiciones de competitividad que operan en ella.

Tal como se señalaba, tomando en cuenta que es innegable la importancia de lo "global", se justifica el analizar si el potencial que tal región posee está siendo aprovechado en su óptimo, de donde surge el problema de estudiar el vínculo entre la gestión regional y su impacto en la competitividad internacional.

De acuerdo con un estudio realizado por SAGARPA para el periodo 2003-2007, productos como la zarzamora, la fresa, el mango, el limón, el pepino, el aguacate y el chile, poseen un potencial de exportación en relación con la variación en la demanda internacional de los productos de interés y la tasa media anual de crecimiento, analizada para los países de Estados Unidos, Canadá, Japón y China (SAGARPA, 2009).

El concepto de competitividad internacional, viene a ser de tal suerte, un referente que permite comparar:

La capacidad que tiene un país para atraer y retener inversiones y talento. Esto se logra cuando los países, regiones o entidades ofrecen condiciones integrales para maximizar el potencial socioeconómico de las empresas y de las personas. Además, debe incrementar de forma sostenida su nivel de bienestar, más allá de las posibilidades intrínsecas que sus propios recursos, capacidad tecnológica y de innovación ofrezcan. Todo ello es independiente de las fluctuaciones económicas normales por las que el país atraviese. (IMC0, 2016)

Sin embargo, los retos que representa el optimizar la región zamorana se vinculan con la productividad agrícola, misma que está basada en el rendimiento de las hectáreas, de los apoyos del gobierno y de los pequeños productores, sin mencionar la incipiente atención prestada al desarrollo de conocimiento e investigación.

Por lo anterior, el presente trabajo tiene como objetivo identificar cómo impactan las variables de recursos productivos, productividad agrícola, actuación del gobierno y relación entre las empresas, sobre la competitividad de Zamora en el plano internacional.

\section{Antecedentes}

En sí mismo el estado de Michoacán cuenta con una posición que lo privilegia en términos geográficos, en tanto que posee salida al mar al ubicarse en la costa meridional del océano Pacífico, así como vías de comunicación terrestre con indicadores logísticos relevantes, como lo demuestran sus "13,380 km de carreteras pavimentadas $(5,728 \mathrm{~km}$ de carreteras de dos carriles y $425 \mathrm{~km}$ de autopista de 4 carriles 0 más" (SEDEC0, Dossier, 2014, pág. 13). 
Michoacán es la " 6 a entidad con mayor kilometraje de vías ferroviarias al contar con 1,242.4 km, con vías de tipo troncales y ramales, secundarias y particulares que durante el 2009 transportaron 2'259,399 toneladas de distintos productos" (SEDECO, Dossier, 2014, pág. 13), lo cual permite que las mercancías procedentes del puerto de Lázaro Cárdenas (mismo que es de altura y cabotaje) sean transportadas en un tiempo aproximado de 72 horas hasta Laredo, Texas, haciendo patente el que Michoacán se encuentre dentro del corredor NASCO y que su principal socio comercial lo constituya el vecino país de Estados Unidos de América (SEDECO, Dossier, 2014). Asimismo, esta entidad también se encuentra a un promedio de tres a cuatro horas de camino con respecto de los centros neurálgicos de la República como son: Guadalajara, Ciudad de México y Toluca. Dentro de las diversas actividades económicas que realiza el estado de Michoacán, su vocación es eminentemente agrícola. Se entiende por actividad económica:

Al conjunto de acciones realizadas por una unidad económica con el propósito de producir un bien o prestar un servicio que se intercambiará por dinero u otros bienes o servicios. En esta definición y por las características de nuestro país se incluye a la producción agropecuaria de autoconsumo. (INEGI, 2001)

La actividad económica total de Michoacán de Ocampo en el 2014 sumó un total de 318,308 millones de pesos $^{1}$ (INEGI, 2014). De las actividades económicas, cabe resaltar que un componente importante para la economía del estado, lo constituyen las exportaciones agrícolas, sobre todo de frescos y congelados.

Zamora, ubicada en la región occidental del estado de Michoacán, es un municipio que destaca en la producción agrícola michoacana y hacia 2010 contribuyó con un estimado de 10,804.9 millones de pesos al PIB estatal (un aproximado de $5 \%$ con respecto del total estatal que fue de 20,384.5 millones de pesos) (González-Estrada \& Gallegos-Cedillo, 2014). Los principales productos de cultivo en Zamora, son: fresa, sorgo, maíz en grano blanco, elote, calabacita

1. Cantidad a precios de 2008. italiana (zucchini), pepino chino, lechuga, entre otros. Con esta vasta producción agrícola, aunque sus montos de producción en toneladas varían en el ranking de los diez primeros lugares, la fresa suele ocupar los primeros tres lugares en promedio.

De acuerdo a la información más reciente del Servicio de Información Agroalimentaria y Pesquera (SIAP), al cierre del año de 2014, la localidad de Zamora cultivó en cíclicos y perennes, una superficie sembrada de 14,080 hectáreas, una superficie cosechada de igualmente 14,080 ha. y un valor de producción de 1,255,051.42 miles de pesos. (SIAP, 2016)

Zamora, que es la localidad de Michoacán que interesa en específico, colinda con Guadalajara, importante centro económico de la República Mexicana y cuya vecindad según queda estipulado en la misma historia agrícola de este lugar, habla del comercio existente entre ambas regiones:

Junto con el establecimiento del porfiriato se desarrolló en el valle de Zamora una fuerte estructura agrícola comercial que hizo patentes sus efectos en diversos ámbitos de la vida económica y social de la ciudad. Según una memoria del estado de Michoacán, fechada en 1883 , se cultivaban en los municipios de Zamora y Jacona 5,960 hectáreas en terrenos irrigados y 6248 en tierras de temporal. Las cifras más relevantes de producción son 2756 toneladas de trigo, 2560 de maíz y 121 de garbanzo. El trigo, hecho harina, se enviaba principalmente a Guadalajara y a otros centros urbanos del occidente. (Toro, 1985, pág. 39)

Desde su fundación, conocida como la famosa hacienda de Tziróndaro, Zamora ha contado debido a su privilegiada posición geográfica en el noroeste del estado de Michoacán, con los climas y suelos propicios para el cultivo, así como con la laboriosidad de la mano de obra local y aledaña.

Conceptos importantes que han delineado la identidad económica de Zamora, lo conforman por un lado, la migración, tanto en su vertiente de inmigración como de emigración, y por el otro la producción agrícola. En efecto, Zamora constituye un referente en producción agrícola nacional, donde la mano 
de obra tanto que se va, como la que llega; ambas vertientes juegan un factor importante ampliamente estudiado dentro del ya famoso fenómeno migratorio mexicano.

De acuerdo con el Consejo Nacional de Población (CONAPO):"Las entidades federativas con más alto grado de intensidad migratoria a Estados Unidos son cuatro y pertenecen a la región tradicionalmente expulsora de migrantes a ese país: Guanajuato, Michoacán, Nayarit y Zacatecas (...)" (pág. 33).

El mismo texto señala que:

En una escala de 0 a 100, el índice de intensidad migratoria de este grupo de entidades se encuentra por arriba de los 3 puntos. Zacatecas es la entidad con más alto índice de intensidad migratoria (4.422), seguida de Guanajuato y Michoacán, las cuales presentan índices muy similares: 3.891 y 3.868 , respectivamente, y Nayarit, que figura en el cuarto lugar, con un índice de intensidad migratoria a Estados Unidos de 3.370. (Uribe, 2010, pág. 33)

En efecto, la región del Centro-Bajío mexicano se caracteriza por sus altos índices de migración, en específico, de migrantes económicos hacia el vecino país del Norte: 97 de cada 100 migrantes guanajuatenses y 98 de cada 100 migrantes michoacanos tienen por destino Estados Unidos de América (INEGI, Cuéntame: información por entidad, 2010).

El concepto "migrante económico" se define de acuerdo con la Organización Internacional para las Migraciones como aquella:

Persona que habiendo dejado su lugar de residencia o domicilio habitual busca mejorar su nivel de vida, en un país distinto al de origen. Este término se distingue del de "refugiado" que huye por persecución o del refugiado de facto que huye por violencia generalizada 0 violación masiva de los derechos humanos. También se usa para hacer referencia a personas que intentan ingresar en un país sin permiso legal y/o utilizando procedimientos de asilo de mala fe. Asimismo, se aplica a las personas que se establecen fuera de su país de origen por la duración de un trabajo de temporada (cosechas agrícolas), llamados "trabajadores de temporada" o temporeros. (0IM, 2015)

Lo que sucede paradójicamente en Zamora es que a la vez que su mano de obra local migra hacia Estados Unidos durante las temporadas de cosecha, lo cual viene a ser la vertiente de la emigración, los jornaleros de regiones circunvecinas, trabajan los campos de cultivo mientras tanto, lo cual viene a ser la parte de la inmigración.

En lo que respecta a la presencia agrícola zamorana, ésta le ha llevado a rebasar las fronteras nacionales sobre todo en cuanto al comercio de determinada frutilla, como lo es la fresa, se refiere. Ésta se ha posicionado como su cultivo estrella, tan sólo en el año de 2012 el cultivo de fresa alcanzó un valor de 995,016,000 miles de pesos, colocando a Michoacán como el primer productor a nivel nacional de dicha fruta y exportándose no sólo a Estados Unidos, sino también a la Unión Europea y Canadá (SEDECO, Guía de Negocios Michoacán, 2012) lo cual coloca a Zamora en la mira internacional como un importante proveedor de dicha materia prima a nivel mundial.

\section{Revisión de Literatura}

La escasez y la necesidad son conceptos vitales implícitos en el estudio de la Economía, misma que constituye un campo del saber íntimamente ligado a la condición humana y al aprovechamiento de los recursos productivos. La teoría económica de Karl Marx, por citar un ejemplo, reconoce fundamentalmente tres factores productivos: tierra, capital y trabajo, así como la escuela neoclásica que a través del teorema Heckscher-Ohlin plantea que la producción de un bien será intensiva en aquel factor que sea más abundante, de tal suerte que los países se especializarán parcialmente (y no absolutamente como afirmaban Smith y Ricardo) en la producción de dicho bien (Cué, 2010).

En los últimos años, han cobrado notoriedad e importancia los procesos de aprendizaje y conocimiento (know-how), así como el uso de la tecnología al considerar la producción de las mercancías. Asimismo, entre los factores de producción que suelen citarse dentro de los enfoques teóricos más 
novedosos y que vienen a ser intangibles en su mayoría, se encuentran:

- Innovación

- Investigación y desarrollo

- Tecnología

- Ciencia

El presente artículo tomará en cuenta tanto los conceptos de desarrollo regional, como de competitividad, dentro de uno de los modelos económicos de reciente creación denominado la Nueva Geografía Económica (NGE), el cual implica reconocer el papel de la geografía y de los factores histórico-institucionales que permean en la economía.

Como antecedentes se tiene que diversas teorías han estudiado la relación existente entre la productividad y la disponibilidad de recursos naturales, así como el papel que juegan las instituciones en su gestión. Desde tiempo de los fisiócratas en el siglo XVIII, la naturaleza era considerada la proveedora neta de riqueza, aunque posteriormente se destaca una concepción más refinada, como ejemplo se encuentra el inglés John Stuart Mill, quien de acuerdo con Alzate (2011) menciona que Mill analizó: “(...) las limitaciones que la disponibilidad de tierra puede imponer a los límites del crecimiento, y concluye al decir que los avances tecnológicos pueden contrarrestar los rendimientos decrecientes de la misma" (p.120), sin embargo, aún entonces no se vislumbraban problemas medioambientales que podría acarrear una sobreexplotación de dicho factor (una nula consideración de las externalidades) (Alzate, 2011).

Conforme la evolución de la teoría se fue dando, hacia finales de los años sesenta del siglo XX, estudiosos tales como Donella Meadows y aquellos que conformaron el "Club de Roma", consideraron relevante tomar en cuenta el crecimiento poblacional, la contaminación medioambiental y el consecuente decrecimiento de la producción y agotamiento de los recursos, comenzando una incipiente subdivisión en la ciencia de la Economía en ramas tan especializadas como la economía ecológica. (Alzate, 2011)

Cabe también destacar que la teoría económica al nutrirse de la llamada escuela neoclásica donde entra en juego el factor de los precios y el valor, es que el comercio internacional se constituye como un foco de atención relevante. Lo anterior implicó a su vez que la Economía requiriese por su parte de otras ciencias para complementar su objeto de estudio; entran en dicho escenario, ciencias como la Administración y las Relaciones Internacionales.

A pesar de lo anterior, dentro de la escuela neoclásica, uno de los principales supuestos es el considerar que la competencia es perfecta y que los costos de producción son crecientes, entonces la ventaja comparativa de un país provendrá de su proporción de factores de producción de que dispone (Cué, 2010). No obstante, en la realidad la competencia no es perfecta, por lo que dentro de los modelos económicos más recientes planteados, se encuentra el de La Nueva Geografía Económica, que tiene relación con los modelos sobre rendimientos crecientes y competencia imperfecta. La NGE propuesto por un grupo de economistas estadounidenses encabezados por Paul Krugman, tiene como idea central que "el crecimiento regional obedece a una lógica de causación circular, en la que los encadenamientos hacia atrás y hacia delante de las empresas conducen a una aglomeración de actividades que se auto-refuerza progresivamente" (Jiménez, 2003, pág. 38).

De acuerdo con Rangel (2014), la importancia del modelo de Krugman radica en cinco puntos torales:

1. “Enfatiza los mercados de competencia imperfecta pues se maximizan las interacciones individuales no racionales; así también, no es absoluto y depende por tanto de particularidades.

2. Es dinámico: conjuga economías de escala, costos de transporte y tamaño de mercado, donde caben como ejemplos las economías de aglomeración y el uso de la tecnología.

3. El modelo no es la realidad.

4. El modelo da lugar a aspectos históricos". (Rangel, 2014)

Asimismo, es destacable que dentro del tema del desarrollo regional, se puntualice lo que se entiende por endógeno: "tiene que ver con el supuesto de que la acumulación de capital y el cambio tecnológico (innovación) son consecuencia de decisiones de inversión tomadas por agentes racionales maximi- 
zadores de ganancias en un determinado contexto histórico" (Jiménez, 2003, pág. 38).

De tal suerte que fenómenos como la globalización son estudiados también dentro del marco de las Relaciones Internacionales, mismas que corresponderían con el estudio en específico de la rama macroeconómica, en tanto que las diversas naciones del mundo se relacionan entre sí para cubrir sus necesidades a través de los satisfactores que unos y otros demandan y ofrecen, respectivamente. La firma de tratados internacionales que contengan cláusulas que regulen temas económicos, las cumbres en que los líderes de los países expresan lo concerniente a la riqueza de sus territorios y su administración, inclusive el modo de negociación que se ve influido por la idiosincrasia de los negociantes en función de la cultura a la que pertenezcan, son tan sólo algunos ejemplos de los puntos en los que ambas, Relaciones Internacionales y Economía, convergen. El ejemplo de nuestro tiempo al respecto es el Trans-Pacific Estrategic Economic Partnership Agreement (TPP) que una vez concretado, aglomeraría a un conjunto de países que representan el $38 \%$ del PIB mundial (Rangel, 2014).

En lo referente al concepto de competitividad internacional, cabe citar a Martha P. López (2010) quien a su vez cita a Michael Porter (2003) al considerar en el marco de una nación que:

La competitividad es la fuente de prosperidad de una nación y el estándar de vida de ésta se determina por la productividad por unidad, de los recursos humanos, de capital y naturales que posea el país. Así, los determinantes de la productividad y del crecimiento de la misma, son por un lado: el contexto macroeconómico político, legal y social para el desarrollo, así como los fundamentos microeconómicos, los cuales se dividen en dos e interactúan: el nivel de satisfacción en las operaciones y en la estrategia de la firma y la calidad del ambiente microeconómico para los negocios, el cual tiene que ver con instituciones políticas, legales y sociales estables, política macroeconómica adecuada que propicia el potencial para mejorar la prosperidad del país. (López, 2010)
Destaca en el concepto de Porter, el apartado macroeconómico que anteriormente se señalaba y que refiere en última instancia al marco supranacional que regula a nivel mundial, pero que también da cuenta de la complementariedad de las Relaciones Internacionales puesto que la misma evolución que ha experimentado el mundo a lo largo de su devenir histórico, involucra cambios dentro de las concepciones en que los negocios internacionales se llevan a cabo, donde no se puede negar que incluso los aspectos históricos que marcaron un parteaguas influyeron en que estos cambios se dieran.

En efecto, los embajadores eran enviados especiales que entre otras actividades, además de fungir como informantes e intermediarios entre las autoridades de sus naciones respectivas, cumpliendo con el mantenimiento de la paz y la negociación sobre el status de los prisioneros de guerra, también allanaban el camino para posteriores negociaciones que entre otras cosas, trataban sobre el intercambio de bienes.

Tal vez el ejemplo más famoso de lo anterior lo refiera la Ruta de la Seda y en específico, el caso del italiano Marco Polo, quien se adentrara en los territorios de la milenaria China y del imperio mongol, construyendo con ello un puente entre ambas culturas que a fin de cuentas suscitó un intercambio no sólo de ideologías, sino también de mercancías.

En la actualidad, las costumbres del cuerpo diplomático de los países distan mucho de las prácticas de antaño, sin embargo, la constante de propiciar el intercambio se mantiene en esencia. Hoy en día, es viable considerar a los empresarios como embajadores per se, en vista de que las empresas transnacionales y las economías de escala basadas en la relocalización de las cadenas de suministro y de producción en países con bajos costos, requieran forzosamente de que las empresas estén dispuestas a entender las manifestaciones culturales locales de la idiosincrasia de la mano de obra contratada.

A su vez, las transformaciones en los medios de comunicación a través de los adelantos en las tecnologías de la información tales como el uso extendido del Internet, propiciaron que de manera "virtual" las fronteras geográficas fueran "desapareciendo" 
paulatinamente, en el sentido de que el uso de estas tecnologías permitió el ahorro de tiempo y dinero, agilizando la manera en que los habitantes del mundo se relacionaran, influyendo en los métodos tanto de management, como diplomáticos.

Todo ello conllevó un impacto en la manera en que el comercio exterior y las instituciones internacionales actuaran, propiciándose marcos regulatorios que normaran de manera homogénea las prácticas de los países tanto en términos logísticos, aduaneros y de normatividad arancelaria.

En lo concerniente al ambiente microeconómico, habría que considerar el papel de las instituciones al interior del país en cuestión. En términos de estudiar una región, como lo es el municipio de Zamora, Michoacán el aspecto microeconómico cobra especial relevancia, de ahí que una de las variables corresponde a las políticas de atracción de inversión extranjera directa y programas de apoyo al sector agrícola por parte del gobierno de Michoacán.

Esta parte se integra si se toma en cuenta el rol que ejerce la ciencia de la Administración como complementaria de la Economía, en tanto que otorga la pauta para comprender, aplicar y diseñar modos de gestionar los recursos de las entidades, en este caso, empresariales para su correcto funcionamiento. De ahí también la justificación para estudiar la variable de la relación entre las empresas del sector agrícola que operan en la región.

En suma, la homologación de criterios en términos de intercambio, los cambios en la gestión de las empresas, la internacionalización de las mismas y el acceso a nuevos mercados, comenzaron a delinear un mundo en el cual la productividad y el comercio exterior cobraban notoriedad. A este respecto, queda claro el por qué la gestión empresarial debería tomar en cuenta el concepto de competitividad internacional como parte crucial que involucra no sólo factores económicos, sino también de política de las naciones y de administración.

\section{Metodología}

Se empleará el método científico con el fin de generar una investigación de tipo descriptiva-explicativa, acorde con el imperativo de generación de conocimiento plenamente comprobable, partiendo de atender las demandas de competitividad y desarrollo regional que prevalecen en el mundo globalizado de hoy.

La hipótesis en tanto "afirmación conjetural entre dos o más variables (...)"se emplea dentro del método científico como "(...) una solución tentativa ante algo que se da por cierto" (Eyssautier, 2002, pág. 196) de modo que en el presente trabajo se pretende comprobar que: La productividad agrícola, los recursos productivos, la relación entre las empresas y los programas gubernamentales son factores que impactan positivamente sobre la competitividad internacional de Zamora, Michoacán.

\section{Variables}

El objetivo del presente trabajo es estudiar el impacto de la productividad agrícola en el cultivo de la fresa zamorana, los recursos productivos involucrados: tierra, capital, trabajo e innovación, la actuación del gobierno a través de programas de apoyo al campo y la relación entre las empresas para medir su impacto sobre la competitividad de Zamora en el plano internacional.

La tabla 1 titulada Variables en estudio da cuenta de los cuatro aspectos antes mencionados, dando a conocer tanto el aspecto a medir de cada una, como el instrumento que habrá de emplearse para tal fin. 
TTabla 1.

Variables en estudio que impactan sobre la competitividad internacional agrícola de la región Zamora

\begin{tabular}{|c|c|c|c|}
\hline Variable dependiente & Variable independiente & Aspecto a medir & Instrumento de medición \\
\hline \multirow{4}{*}{$\begin{array}{l}\text { Competitividad internacional } \\
\text { agrícola de la región Zamora }\end{array}$} & Recursos productivos & $\begin{array}{l}\text { Herramientas con que se } \\
\text { cuenta para producir }\end{array}$ & $\begin{array}{l}\text { - Tierra: superficie sembrada y } \\
\text { superficie cosechada. } \\
\text { - Trabajo: jornaleros temporales y } \\
\text { fijos. } \\
\text { - Capital: dinero invertido en el } \\
\text { campo. } \\
\text { - Innovación: conocimiento científico } \\
\text { al servicio de la agroindustria. }\end{array}$ \\
\hline & Productividad agrícola & $\begin{array}{l}\text { Capacidad productiva } \\
\text { traducida en mercancía que } \\
\text { se coloca en un punto de } \\
\text { venta fuera del país }\end{array}$ & $\begin{array}{l}\text { Cantidad de exportaciones del } \\
\text { producto estrella de Zamora: la fresa. }\end{array}$ \\
\hline & Actuación del gobierno & $\begin{array}{l}\text { Políticas económicas con } \\
\text { marcos favorables para el } \\
\text { comercio }\end{array}$ & $\begin{array}{l}\text { Programas de apoyo a la agricultura } \\
\text { a través de la SAGARPA. }\end{array}$ \\
\hline & Relación entre empresas & $\begin{array}{l}\text { La interacción entre los } \\
\text { empresarios que pueda } \\
\text { traducirse en alianzas } \\
\text { estratégicas }\end{array}$ & Membresía a consejos empresariales. \\
\hline
\end{tabular}

Fuente: Elaboración propia.

\section{Resultados}

\section{Recursos productivos}

Los recursos productivos tomados en cuenta en esta investigación refieren a: tierra, capital, trabajo e innovación.

\section{Tierra}

La tierra ha sido considerada, desde tiempo de los fisiócratas, como un factor productivo esencial, posteriormente Marx consideraría que la ganancia del terrateniente se obtendría a partir de la renta cobrada por el mismo, en tanto se le cultivara por el jornalero; en efecto, precisamente al hablar de productividad agrícola, ésta no puede ser entendida si se deja pasar por alto la tierra. Con el fin de medir el aprovechamiento de la tierra, se comparan los datos correspondientes a la superficie sembrada contra la superficie cosechada (Véase Figura 1).

Al cotejar dichos datos a lo largo de 11 años para el cultivo específico de la fresa en Zamora se puede observar que entre ellas hay un rango de diferencia que en promedio se mantuvo en 55.03 hectáreas desperdiciadas. Llama la atención que en los años 2005 a 2009, dicho diferencial se mantuvo en cero, indicando lo anterior que durante dicho periodo justamente las superficies sembrada y cosechada se aprovecharon al máximo, patrón que vuelve a repetirse en el 2012 y 2014. Destaca también que el año de 2013 obtuvo el rango de diferencia más notorio con 122.50 hectáreas perdidas, por lo que el promedio de desperdicio obtenido no puede reflejar con certeza el nivel de diferencia entre las superficies. 
Clío América - Universidad del Magdalena • Clío América • Universidad del Magdalena • C a Ane ica $\bullet$ Universidad del Magdalena $\bullet$ Clío América $\bullet$ Universidad del

- Figura 1.

Comparativa entre la superficie sembrada y la superficie cosechada de fresa en Michoacán

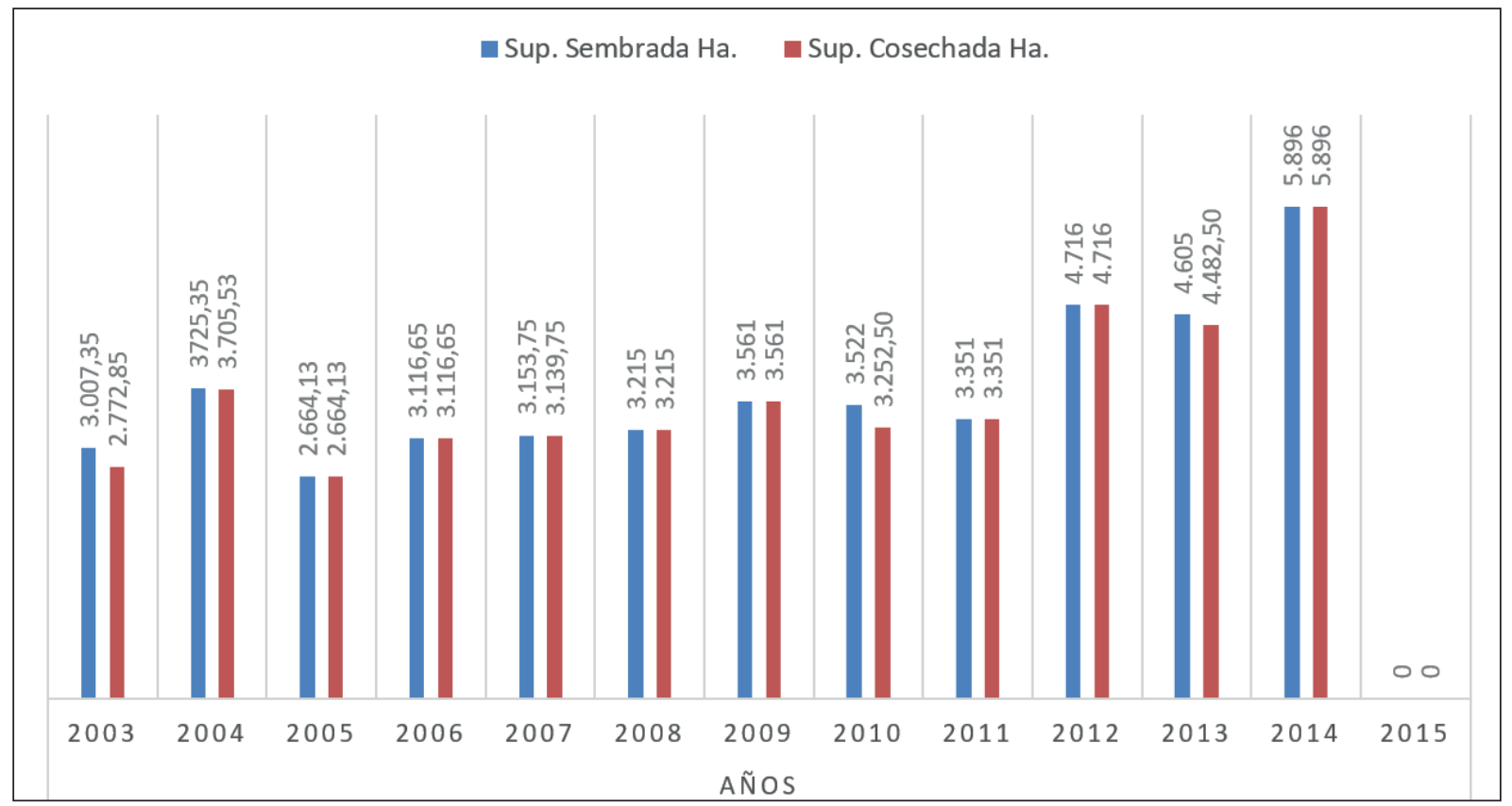

Fuente: elaboración propia basada en datos del SIAP (2015)

\section{Capital}

El capital refiere a la serie de activos empleados en la generación de otros bienes. El gobierno mexicano provee de determinado presupuesto a cada una de las secretarías, tal como se enuncia a continuación, según el gasto programable que dio a conocer la Secretaría de Hacienda y Crédito Público (SHCP) de México en 2012:

TTabla 2.

Participación presupuestal de los Ramos Administrativos en porcentaje

\begin{tabular}{|l|c|}
\multicolumn{1}{|c|}{$\quad$ Participación de los Ramos Administrativos } & Porcentaje (\%) \\
\hline Educación, Ciencia y Tecnología & $29 \%$ \\
\hline Seguridad Pública y Nacional & $14 \%$ \\
\hline Salud & $12 \%$ \\
\hline Desarrollo Social & $9 \%$ \\
\hline Comunicaciones y Transportes & $9 \%$ \\
\hline
\end{tabular}




\section{Continuación Tabla 2.}

\begin{tabular}{|l|c|}
\multicolumn{1}{|c|}{ Participación de los Ramos Administrativos } & Porcentaje (\%) \\
\hline Agricultura, Ganadería, Desarrollo Rural, Pesca y Alimentación & $8 \%$ \\
\hline Medio Ambiente y Recursos naturales & $6 \%$ \\
\hline Hacienda y Crédito Público & $5 \%$ \\
\hline Gobernación & $3 \%$ \\
\hline Otros & $3 \%$ \\
\hline Economía & $2 \%$ \\
\hline
\end{tabular}

Fuente: Elaboración propia basada en el Presupuesto ciudadano de la SHCP (2012)

Tal como se observa en la tabla anterior, el presupuesto que destina el gobierno es de $8 \%$ al rubro de Agricultura, Ganadería, Desarrollo Rural, Pesca y Alimentación, mientras que los tres primeros rubros que reciben mayor atención lo constituyen: Educación, Seguridad y Salud.

FAOSTAT también puntualiza que los desembolsos de los gastos de gobierno dedicados a la agricultura, desde el año 2001 hasta el 2013 que corresponde al último dato actualizado, ha sido siempre en un porcentaje menor o igual a $10 \%$ (FAOSTAT, 2013).

\section{Trabajo}

La mano de obra refiere a los individuos que dedican su tiempo y esfuerzo en la producción de un bien o en la prestación de un servicio. Según datos del Banco de Información Económica del INEGI (2010) (Véase Figura 2: Trabajadores permanentes y eventuales asegurados ante el Seguro Social dedicados a la Agricultura, Ganadería, Silvicultura, Caza y Pesca), en los últimos 12 años, la mano de obra dedicada en México a las actividades primarias, se ha mantenido en un promedio de 4'332,034 trabajadores dedicados a dicho rubro.

Por su parte, de acuerdo con la Food and Agriculture Organization of the United Nations (FAOSTAT), en México la distribución laboral dedicada a la agricultura, ha disminuido con los años, como se muestra en la siguiente Figura 3: Distribución laboral agrícola de México.

La información de la FAOSTAT contrasta con los resultados obtenidos por el Fondo Sectorial de Investigación en Materia Agrícola, Pecuaria, Acuacultura, Agrobiotecnología y Recursos fitogenéticos que dio a conocer que:

Para un ciclo de producción y cosecha de fresa en sistema tradicional se requieren de 460 jornales por hectárea por ciclo; mientras que bajo un sistema semi tecnificado se requieren de 700 , en tanto que para la producción y cosecha con macrotúnel se requieren de aproximadamente 1,100 jornales por hectárea. Tan sólo en la región de Zamora-Ciénega de Chapala en el 2010 se requirieron de un total de $4^{\prime} 066,860$ jornales. Para las hectáreas cultivadas bajo sistema tradicional se requirieron de 209,760 jornales, para las semi tecnificadas se necesitaron de 551,600 jornales; mientras que para las tecnificadas se requirieron de 3`305,500 jornales ya que el número de hectáreas fue de 3,005. (Fondo Sectorial de Investigación en Materia Agrícola, Pecuaria, Acuacultura, Agrobiotecnología y Recursos Fitogenéticos, 2012, p. 4)

Lo anterior refleja que si bien aún permea el sistema tradicional de cultivo, paulatinamente la tendencia se dirige hacia la tecnificación. 
Clío América - Universidad del Magdalena • Clío América • Universidad del Magdalena • C o Ane ica $\bullet$ Universidad del Magdalena $\bullet$ Clío América $\bullet$ Universidad del

Estudio de la región Michoacana de Zamora como polo de competitividad internacional agrícola

\section{- Figura 2.}

Trabajadores permanentes y eventuales asegurados ante el Seguro Social dedicados a la Agricultura, Ganadería, Silvicultura, Caza y Pesca

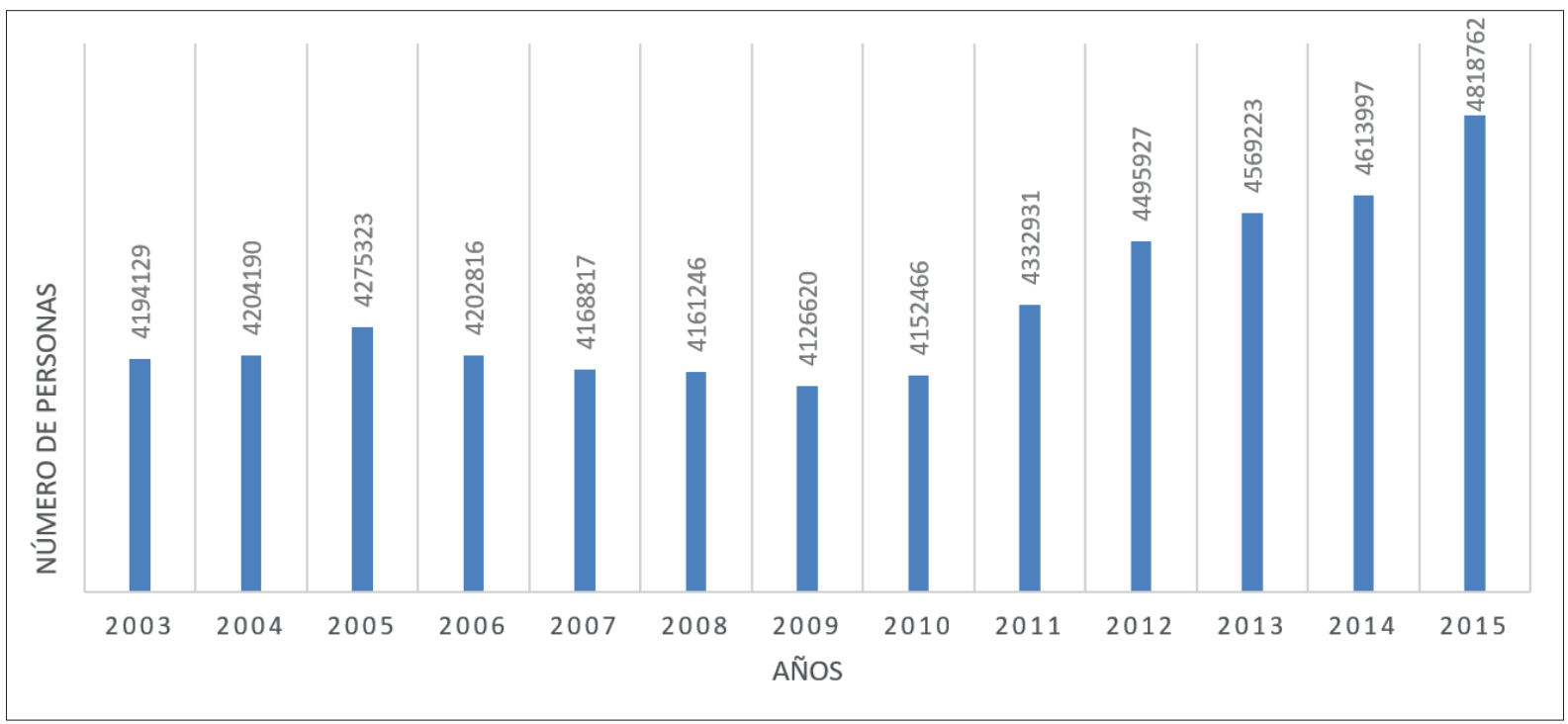

Fuente: elaboración propia basada en datos del BIE/INEGI (2016)

\section{- Figura 3.}

Distribución laboral agrícola de México

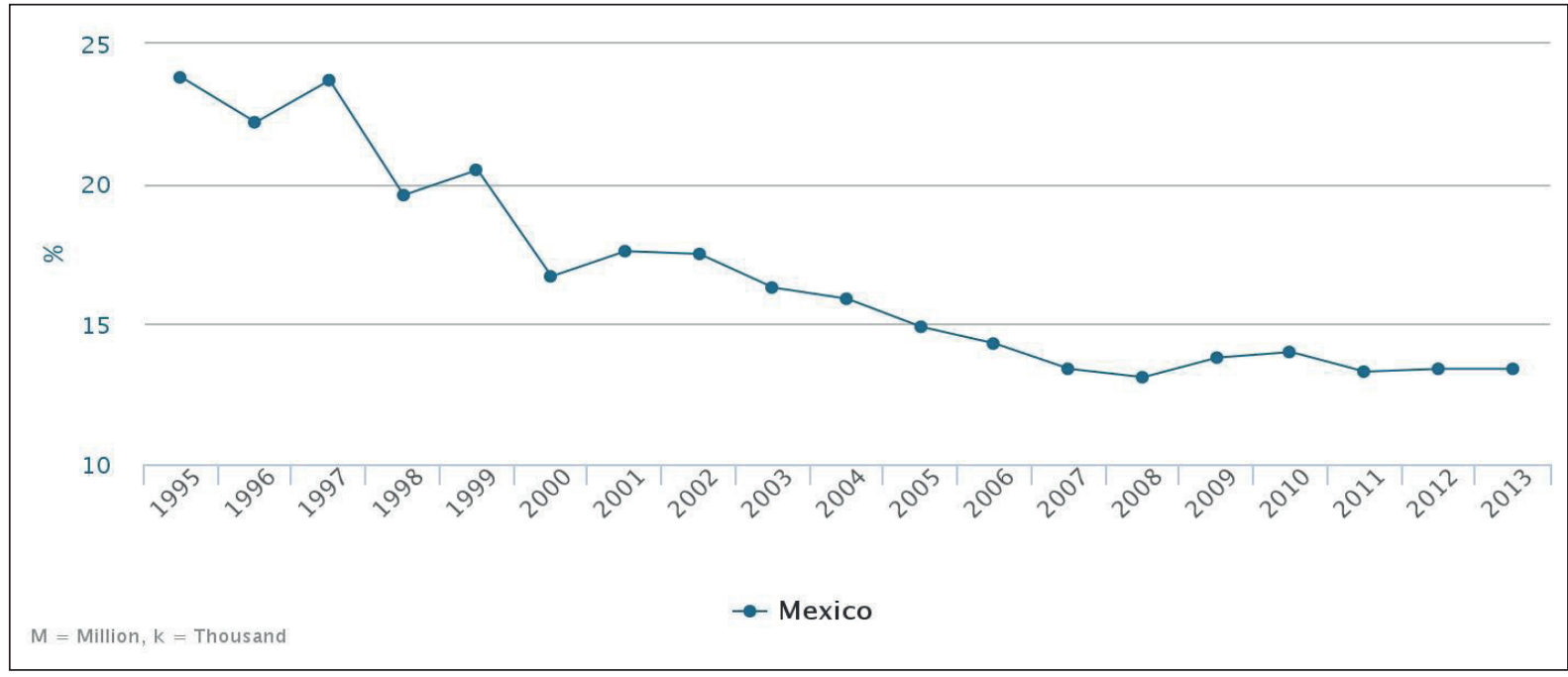

Fuente: obtenido de http://faostat3.fao.org/browse/R/OE/E (FAO, 2015) 


\section{Innovación}

La innovación se define en términos de creatividad, donde no necesariamente se requiere generar algo nuevo de la nada, sino donde la modificación de lo preestablecido genera posibilidades no contempladas con anterioridad. En dicho sentido, la innovación no es específica de un campo del saber o de otro y está intimamente ligada al desarrollo de conocimiento científico.

La innovación agrícola, en ese sentido apunta a la generación de variedades para su cultivo, que requieren de una serie de pruebas que los certifiquen como productos no sólo cultivables e inocuos, sino del gusto del consumidor final.

"En el Colegio de Postgraduados, con el apoyo financiero de la Fundación Produce Michoacán, A. C., se han obtenido nuevas variedades de fresa, entre las que destacan 'CP Zamorana' (CP 02-01) y 'CP Jacona' (CP 02-04), como nuevas variedades mexicanas ya registradas en el catálogo del Servicio Nacional de Inspección y Certificación de Semillas (SNICS)" (Fondo Sectorial de Investigación en Materia Agrícola, Pecuaria, Acuacultura, Agrobiotecnología y Recursos Fitogenéticos, 2012).

La validación de estas nuevas variedades siempre se hace en comparación con las variedades extranjeras empleadas, mismas que de acuerdo al trabajo académico se descubrió que representan un costo elevado para los productores, dado que requieren ser importadas de Estados Unidos (de donde provienen la mayoría) que corresponden a las variedades Festival, San Andreas y Albión, dado que no solamente se requiere comprar la planta madre, sino también realizar los trámites aduanales, los fletes y traslados además del pago de regalías.
Se destaca al respecto la actuación de la Fundación Produce Michoacán A.C., el Colegio de Postgraduados y la Universidad Michoacana de San Nicolás de Hidalgo en Uruapan, todas ellas instituciones abocadas al fortalecimiento y generación de variedades mexicanas de fresa mediante la selección de genotipos. Sin embargo, aún resta que se aprueben para producción y comercialización, quedando pendiente su aceptación en la agroindustria.

Una vez mencionados los recursos necesarios para la producción, se procede a analizar los niveles de producción de fresa tal como se verá en el siguiente apartado, con el fin de calcular la productividad agrícola.

\section{Productividad agrícola}

Con respecto de la productividad agrícola de la región de Zamora, se estudiarán los niveles de producción de fresa bajo la definición más básica de productividad, la cual se entiende como "el resultado de dividir el total de factores de salida, como bienes, entre los de entrada, como recursos" (Cantú, 1995).

De acuerdo con García Cantú, quien a su vez hace referencia a la Oficina Internacional del Trabajo que define a la productividad mediante la siguiente ecuación:

\section{Productividad $=$ Bienes y servicios \\ Recursos invertidos en producirlos}

De acuerdo con el SIACON, la producción (en toneladas) de fresa a nivel nacional a lo largo de 11 años, es decir, en el periodo comprendido del año 2003 al 2014, fue de un total de 2,950,497.68 toneladas. Los volúmenes de producción por año se muestran en la Figura 4: Comparativa entre el volumen de producción nacional y el volumen de producción de Michoacán de fresa (en toneladas), adjunta a continuación: 


\section{- Figura 4.}

Comparativa entre el volumen de producción nacional y el volumen de producción en Michoacán de fresa (en toneladas)

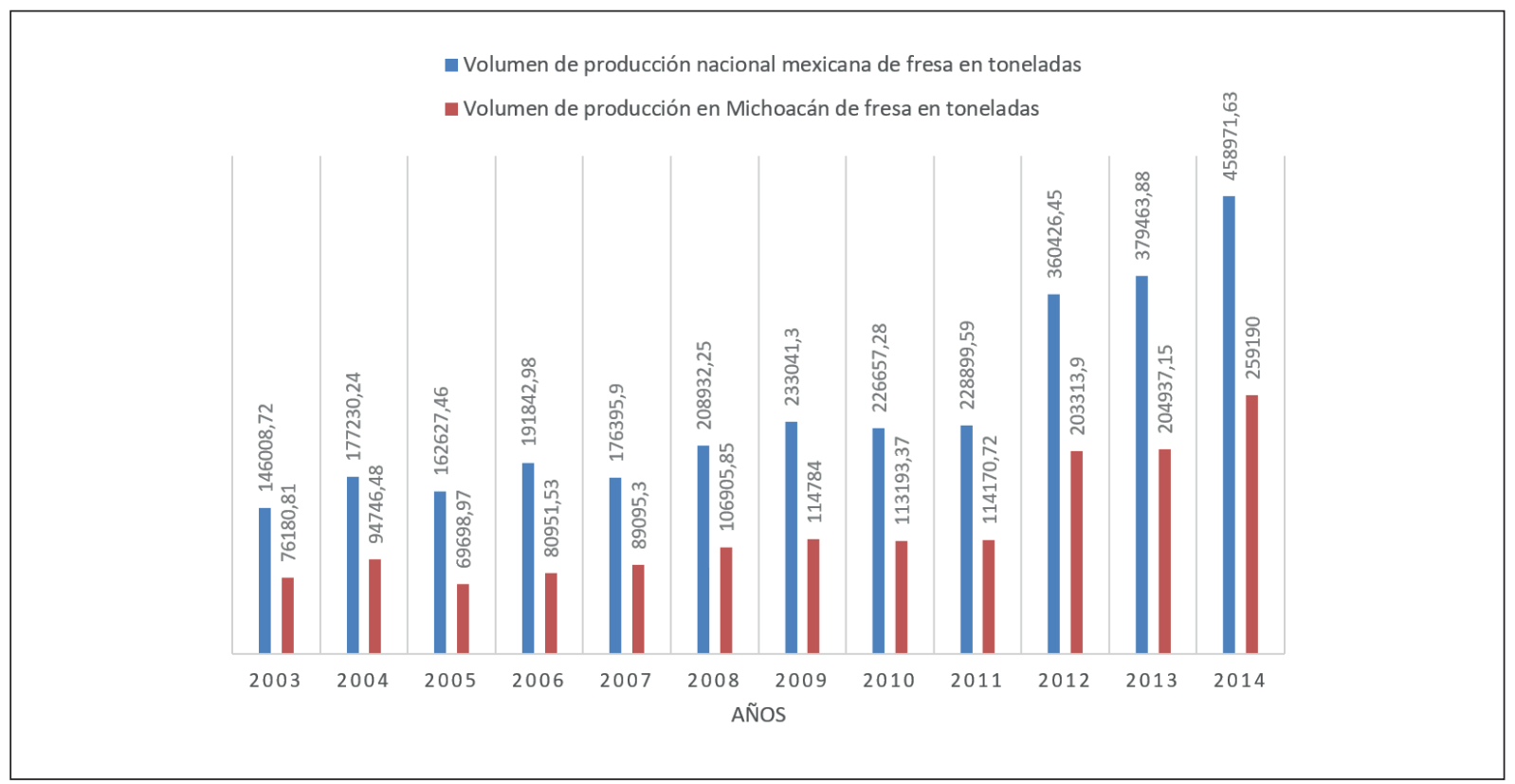

Fuente: elaboración propia basada en datos del SIACON (2015)

Como se observa en la Figura 4: Comparativa entre el volumen de producción nacional y el volumen de producción de Michoacán de fresa (en toneladas) mostrada anteriormente, el volumen de producción de fresa en el plano nacional, es decir aquella cultivada a lo largo de todo México, ha ido aumentando gradualmente a lo largo de los años, salvo ligeras caídas en los años 2005, 2007 y 2010, donde respectivamente se bajaron $-14,602.78$ tons, $-15,447.08$ tons. $Y-6,384.02$ tons. con respecto de los años que les precedieron.

Tal como lo muestra la gráfica, conviene comparar la información nacional, con la que aporta uno de los estados agrícolas más importantes en el país, como lo es Michoacán.

De acuerdo con lo observado en la Figura 4: Comparativa entre el volumen de producción nacional y el volumen de producción de Michoacán de fresa (en toneladas), se puede afirmar que el nivel de producción michoacano sigue una tendencia de crecimiento gradual, salvo las caídas que tuvo du- rante los años 2005 y 2010 siendo más alarmante la diferencia entre los años 2004 y 2005 donde bajó $-1,041.40$ toneladas, en comparación a las -308.50 disminuidas entre 2009 y 2010.

En lo referente a la comparativa entre la producción nacional y la de Michoacán, se observa que, durante dicho periodo, el total de producción nacional fue de 2,950,497.68 toneladas, contra el total estatal de1,527,168.08 toneladas de fresa acorde con la fórmula (1) propuesta.

Tomando el total nacional como el $100 \%$, se calcula que Michoacán aportó el 51.75 \% de dicho monto. Es decir, el estado de Michoacán aporta poco más de la mitad de producción de fresa del país:

Si 2,950,497.68 = $100 \%$, entonces: $1,527,168.08=x \%(1)$

Donde $x=(1,527,168.08 * 100) / 2,950,497.68$

Por lo tanto: $1,527,168.08=51.75 \%$ 
Por ello se puede afirmar que la producción de fresa en Michoacán, lo posiciona como el principal estado de la República Mexicana como productor de dicha frutilla.

En efecto, Michoacán es el principal productor de fresa en México, debido a la producción que se lleva a cabo en el valle de Zamora (véase Figura 5), donde de acuerdo con el Servicio de Información Agroalimentaria y Pesquera (SIAP), los datos de producción de fresa desde el año $2003^{2}$ hasta el 2014 se posicionan entre los primeros tres lugares de diez, de los cultivos que más se siembran, cosechan y producen. Por su parte, los montos anuales de producción en toneladas de la fresa en Zamora, sumaron a lo largo del periodo comprendido entre el 2003 y el 2014, la cantidad de $\$ 3{ }^{\prime} 788,545.73$ miles de pesos (SIAP, 2016).

\section{- Figura 5.}

\section{Producción anual en toneladas de fresa en Zamora y en Michoacán}

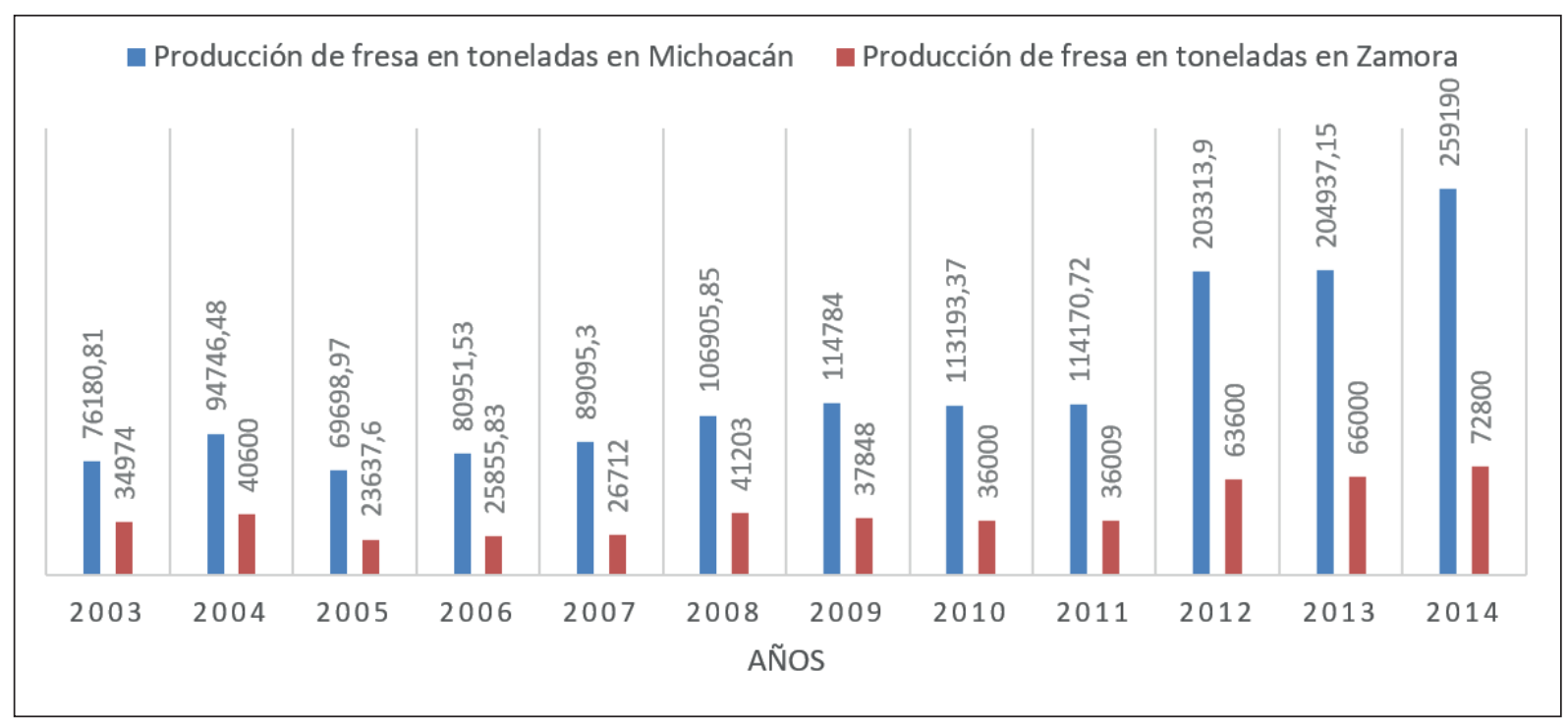

Fuente: elaboración propia basada en datos del SIAP (2015)

Tal como se observa en la Fig. 5: Producción anual en toneladas de fresa en Zamora y en Michoacán, la producción de fresa en Michoacán comparada con la producción de fresa en Zamora, refleja que la contribución de esta región es de aproximadamente una tercera parte. A su vez, a pesar de las "caídas" que se detallaban en la Fig. 4, la producción michoacana en general y a lo largo de 11 años ha ido incrementándose paulatinamente con un repunte relevante en el año 2012 tras la mala racha que presentó desde el 2008 hasta el 2011.

De modo que, tal como se observa en la Figura 6: Exportaciones anuales de fresa de México en toneladas, y al contrastarlo con la cantidad de exportación de fresa que México coloca anualmente en el mundo, teniendo en cuenta que en promedio la tercera parte de dicha producción proviene de Zamora, entonces se puede confirmar que la competitividad de la fresa cultivada en Zamora es un ejemplo de competitividad internacional.

2. Aun cuando el SIAP posee un registro a partir del año 1980, los datos de producción para el municipio de Zamora, Michoacán tan sólo están asentados desde el año 2003. 


\section{- Figura 6.}

\section{Exportaciones anuales de fresa de México en toneladas}

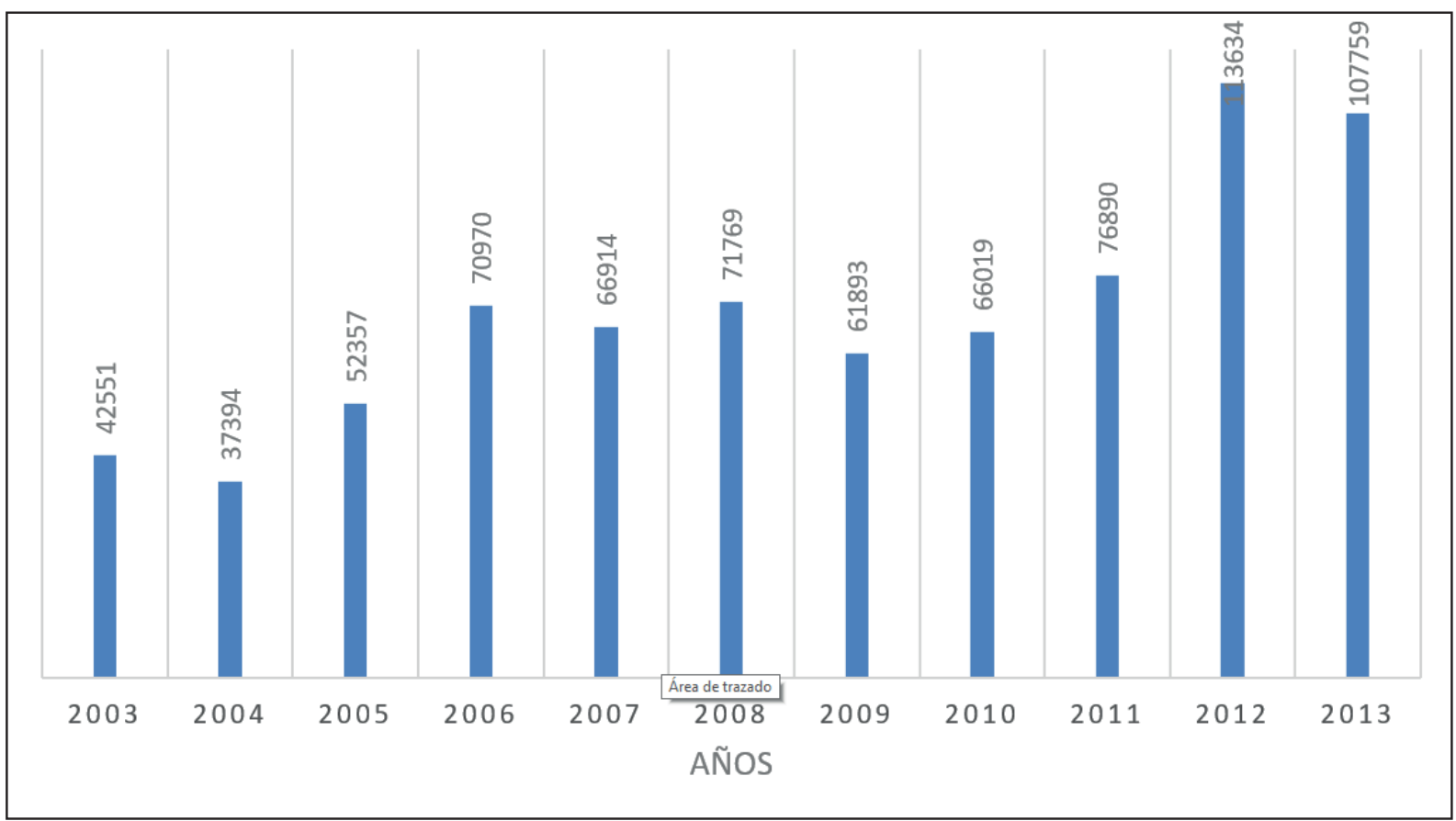

Fuente: elaboración propia basada en datos de la FAOSTAT (2015)

Los principales destinos a los cuales se dirige la fresa mexicana de exportación, lo constituyen Estados Unidos y Canadá, mismos que en el año de 2010 sumaron juntos la cantidad de 155, 265.92 toneladas de fresa.

Tan sólo en el año 2010, Estados Unidos es el país que acaparó el destino de las exportaciones freseras mexicanas con un $98.06 \%$, siguiéndole Canadá con $1.5 \%$ y el resto de países como: Brasil, Japón, Alemania, Francia, Holanda, Australia, Belice y Jamaica que juntos apenas suman el $0.44 \%$. Dicha tendencia de acaparamiento, aún hoy continúa (SIAP, 2016).

Siguiendo la fórmula de productividad agrícola, donde se calcula al dividir los bienes producidos entre los recursos empleados, es posible cruzar la información de la producción anual de fresa de Zamora, contra las hectáreas realmente aprovechadas (tomando en cuenta que existe un diferencial entre la superficie sembrada y la superficie cosechada), de donde se obtiene la siguiente tabla: 
Tabla 3.

Productividad agrícola en función de la superficie cosechada en el periodo 2003-2013

\begin{tabular}{|c|c|c|c|c|}
\hline Año & $\begin{array}{l}\text { Nivel de producción } \\
\text { de fresa en Zamora }\end{array}$ & Hectárea cosechadas & Rendimiento (ton/ha) & $\begin{array}{l}\text { Rendimiento de la fresa que } \\
\text { posee Michoacán según datos del } \\
\text { SIACON (ton/ha) }\end{array}$ \\
\hline 2003 & 34,974 & 1,206 & 29.01 & 27.474 \\
\hline 2004 & 40,600 & 1,450 & 28 & 25.569 \\
\hline 2005 & $23,637.6$ & 804 & 29.40 & 26.162 \\
\hline 2006 & $25,855.83$ & 861 & 30.3 & 25.974 \\
\hline 2007 & 26,712 & 840 & 31.80 & 28.377 \\
\hline 2008 & 41,203 & 1,084 & 38.01 & 33.252 \\
\hline 2009 & 37,848 & 996 & 38 & 32.234 \\
\hline 2010 & 36,000 & 900 & 40 & 34.802 \\
\hline 2011 & 36,009 & 900 & 40.01 & 34.071 \\
\hline 2012 & 63,600 & 1,200 & 53 & 43.112 \\
\hline 2013 & 66,000 & 1,200 & 55 & 45.719 \\
\hline Promedio & $39,312.6755$ & & 37.50 & 32.43 \\
\hline
\end{tabular}

Fuente: elaboración propia basada en datos SIAP (2015), SIACON (2015)

Es posible observar que el rendimiento de Zamora obtuvo un promedio de 37.50 en contraste con el 32.43 que posee Michoacán, de donde se deduce que el sistema de producción imperante en Zamora rebasa el desempeño estatal, siendo así, la paulatina tecnificación del campo dejó atrás la técnica tradicional, donde la tecnificación implica la instalación de los denominados macrotúneles: "Bajo este sistema se utilizan principalmente aguas subterráneas 0 agua superficial limpia (manantial). Se emplea acolchado y la totalidad de la superficie está cubierta con lonas pláticas" (CONAFRE \& Comité de la Agroindustria y Productores , 2011, pág. 6).

\section{Programas gubernamentales}

SAGARPA es la Secretaría a nivel federal encargada principalmente de la promoción de las tres principales actividades primarias: agricultura, ganadería y pesca.

De los programas gubernamentales que posee SAGARPA hacia el 2016, destacan de los dedicados al campo:

1. Programa de Apoyo a la Agricultura

2. Programa de Productividad y Competitividad Agroalimentaria 
3. Programa de Sanidad e Inocuidad Agroalimentaria 4. Programa de Productividad Rural

5. Programa de Concurrencia con las Entidades Federativas

6. Programa de Comercialización y Desarrollo de Mercados

(Se omitieron por obviedad los dirigidos al apoyo ganadero y acuícola por no ser estos últimos, temas de este trabajo).

De dicha lista, aquellos que están directamente relacionados con la agricultura como tal, están dirigidos a las denominadas Unidades Económicas Rurales y Agrícolas (que en este trabajo se abrevian como UERA), mismas que constituyen la población objetivo de los programas relacionados con el apoyo al campo.

Destaca el Programa de Apoyo a la Agricultura, de Productividad y Competitividad Agroalimentaria, de Sanidad e Inocuidad Agroalimentaria, de Productividad Rural y de Comercialización y Desarrollo de Mercados, dado que fungen como un todo al momento de coadyuvar en el fomento a la agroindustria.

El Programa de Fomento a la Agricultura dedica su objetivo a incrementar el nivel tecnológico de los cultivos, incremento de la infraestructura, equipo y servicio en las cadenas de valor, capital de trabajo, mecanización y equipamiento, así como investigación y transferencia de tecnología.

Por su parte, el Programa de Comercialización y Desarrollo de Mercados posee un enfoque económico relevante y complementario a la labor que realizan secretarías y fideicomisos netamente dedicados a la asesoría comercial para los productores, como son Secretaría de Economía y ProMéxico. Aun cuando de primer momento se pudiera deducir que hubiera un empalme de funciones, el enfoque de SAGARPA a través del programa ACERCA es diferente.

En primer término porque los productos que ACERCA promociona se llevan ante ferias comerciales a nivel internacional únicamente focalizadas en el sector agroalimentario, lo cual como el nombre del programa lo indica, acerca de primera mano a los vendedores con los compradores. Por otra parte, ACERCA centra su atención sólo en aquellos productos frescos que por lo tanto no poseen valor agregado y que constituyen, de acuerdo a las estadísticas de exportaciones del SIAVI, es la realidad para la mayor parte del comercio de exportación de materia prima de México.

La crítica más contundente que suelen recibir los programas gubernamentales, es aquella que manifiesta que aproximadamente el $50 \%$ de los productores no están informados de los beneficios potenciales de estos programas que, ante la falta de publicidad, son desaprovechados (Amador, 2008). De ahí que la publicidad y capacitación de las UERA se torna indispensable, pues dado que la mayoría de los productores siguen teniendo técnicas tradicionales de cultivo como se vio en el apartado de productividad agrícola, ello aumenta sus costos de producción y disminuye el rendimiento obtenido.

Uno de los problemas cruciales en la tecnificación del campo, lo constituyen los sistemas de riego debido en parte a que en función del abastecimiento de agua que requieren los centros urbanos, suele haber desacuerdos sobre la distribución del agua. En esos casos, conviene apelar a los apoyos que el gobierno puede otorgar, un ejemplo lo constituiría el programa de SAGARPA denominado Programa de Productividad Rural, cuyo objetivo es el de "apoyar a los productores agropecuarios de las regiones con poca disponibilidad de agua y procesos de erosión para aprovechar sustentablemente los recursos naturales asociados con sus actividades productivas" (SAGARPA, 2016).

En efecto, el sistema tradicional posee un rendimiento por hectárea menor al que presentan otros sistemas de producción como el semi-tecnificado y el tecnificado, donde se obtienen rendimientos de 32 y 80 toneladas por hectárea, respectivamente (Fondo Sectorial de Investigación en Materia Agrícola, Pecuaria, Acuacultura, Agrobiotecnología y Recursos Fitogenéticos, 2012). Lo anterior redunda en mayores costos de producción, al requerir mayores pesticidas por ejemplo, para evitar las enfermedades a las que pueden estar propensas las frutas. 
Al respecto, existe el programa de Sanidad e Inocuidad Agroalimentaria, que es un requisito indispensable para certificar de acuerdo a estándares fitosanitarios los productos, de acuerdo al sub-programa de Sanidad Federalizado y que garantiza la seguridad agroalimentaria. De no contar con dichos certificados, entonces no es posible la comercialización de los productos, en primer término para el mercado nacional y en segundo, para el de exportación, donde de acuerdo a las regulaciones fitosanitarias de cada país, es necesario cumplir con certificaciones particulares.

Otro de los riesgos a los cuales se exponen los productores al mantener un sistema tradicional de cultivo, es el de la baja protección que cuentan sus parcelas ante los desastres naturales. El mismo programa de Productividad Rural a través del sub-programa Atención a Siniestros Agropecuarios fue creado precisamente para contrarrestar dichos efectos.

Un punto igual de importante lo constituye el apoyo que recibe los pequeños y medianos productores, en comparación con los grandes empresarios, lo cual conlleva a considerar la importancia de la relación que tienen las empresas que deciden sumar esfuerzos y constituirse en consejos empresariales, como se explica en el siguiente apartado.

\section{Relación entre empresas}

Las principales organizaciones en el ramo fresero se encuentran en tres estados de la República Mexicana: Jalisco, Guanajuato y Michoacán. Dentro de ellos es posible mencionar a las siguientes:

- Comité Nacional de la Agroindustria y Productores de la Fresa, A.C.

- Consejo Nacional de la Fresa, A.C.

- Consejo Estatal de Productores de Fresa del Estado de Guanajuato, A.C.

- Consejo Estatal de la Fresa de Michoacán, A.C.

- Unión Agrícola Regional de Productores de Fresa y Hortalizas del Valle de Zamora.

- Sociedades de Producción Rural y Sociedades anónimas relacionadas con el cultivo de la Fresa.

\section{El Caso de Agrana}

Con lo visto anteriormente y basándose en el modelo teórico planteado al principio de esta investigación que corresponde al de la Nueva Geografía Económica (NGE), mismo que se encuadra dentro del tópico del desarrollo regional, se puede citar como caso exitoso el de la empresa Agrana, mismo que ejemplifica cómo la correcta mancuerna de cada una de las variables, hace posible la creación de una empresa con competitividad internacional.

A continuación se plantea un breve panorama sobre dicha transnacional: "AGRANA Fruit México S.A. DE C.V. nació en 1981 como SIASPORT en la Ciudad de Zamora, Michoacán, México. Fue establecida dentro de las instalaciones de una empresa del ramo, siendo una filial de SIAS MPA (Francia), posteriormente como Atys y ahora como AGRANA (...)" (Agrana Investment Corp., 2016).

Conocida en sus orígenes como SIAS MPA (Société Industrielle et Agricole de la Somme), hacia 1981 comenzó desde Francia su política de expansión, decidiendo invertir estratégicamente en tres países: Alemania, Estados Unidos y México. Desde 2006 opera en diversos países del mundo, con 51 plantas y ostenta un privilegiado lugar como productor mundial de almidón y azúcar para Europa Central, así como líder mundial en productos elaborados con frutas (Agrana France, 2016).

En Jacona, región vecina a Zamora, dicha empresa emplea a poco más de 600 personas y constituye un polo de desarrollo indiscutible. Representa la división de frutas del corporativo, con productos congelados y pasteurizados tanto para la industria repostera, heladera, entre otras (Global Standards, 2012). Actualmente cuenta con la certificación FSSC 22000 (Food Safety System Certification) medida de inocuidad creada en 2004 y respaldada por la fundación de la Food Drink Europe y reconocido por la Iniciativa Mundial de Seguridad Alimentaria (GFSI) (FSSC, 2016).

Se concluye que el caso de la empresa Agrana ejemplifica el perfil de una empresa competitiva a 
nivel internacional por las siguientes razones: al ser transnacional, está consciente de la importancia que ostenta la ubicación geográfica; su planta en Jacona se ha especializado en el punto fuerte de la región: los productos en fresco y congelados; asimismo, está en constante certificación con lo cual no sólo atiende las políticas gubernamentales sino los criterios que rigen el comercio internacional y por último, da pauta al desarrollo regional a través de los empleos que genera.

\section{Conclusión}

Los factores productivos considerados por la teoría marxista y de intensidad de los factores productivos de Heckscher-Ohlin que refieren a: tierra, capital y trabajo, si bien son la base desde la cual se parte para generar productividad, es notorio que en el sistema económico actual, requieren de factores intangibles complementarios para obtener competitividad, entrando en juego el concepto de la innovación, la investigación, la ciencia y la tecnología.

Además, es posible observar también cuán determinante es el papel que juega la geografía en la integración económica y la dinámica del comercio internacional, toda vez que como se observó en los apartados de Antecedentes y de Productividad Agrícola, la relación dependiente con los Estados Unidos de América, visible no sólo en la diáspora de mano de obra migrante y de la centralización en la exportación de fresa hacia dicho país, plantea una problemática también en cuanto a la importación de plantas madre y variedades estadounidenses, se refiere, mismas que generan elevados costos a los productores.

De lo anterior es que se torna relevante el aspecto de la innovación y la ciencia como factores productivos intangibles, donde de lograrse exitosamente la serie de evaluaciones y certificaciones para el cultivo de las variedades de fresa Zamorana y Jacona, se lograría una competitividad internacional sustentada en el desarrollo regional dado que se involucraría a un mayor número de beneficiarios locales además de las empresas, como son: los centros de investigación de universidades y asociaciones civiles.
A pesar del sistema de producción tradicional que imperó en Zamora, la tecnificación que ha ido adquiriendo con los años le ha permitido aumentar su producción, tal como da cuenta el Comité de la Agroindustria y Productores de la Fresa, A.C. en conjunto con el CONAFRE (2011) : “Cada vez es mayor el número de toneladas exportadas por Michoacán gracias al aumento en la producción de una fresa de mayor calidad debido a que ha crecido el número de hectáreas con sistema de macrotúnel" (págs. 3-5), es por ello que es viable afirmar que la calidad de su producción y sus rendimientos dan testimonio de un sector agrícola fuerte que pudiera llevarse a su óptimo toda vez que se genere una mancuerna más aterrizada con el sector educativo, pero así también con el gubernamental, donde la competitividad internacional basada en el desarrollo regional se refleje claramente.

\section{Referencias Bibliográficas}

Agrana France. (2016). Agrana. Obtenido de La plus-value naturelle: http://www.agrana.fr/qui-sommes-nous/histoire/

Agrana Investment Corp. (2016). Agrana. Obtenido de Agrana en México: http://www.agrana.com.mx/agrana-en-mexico/ historia/

Álzate, M. S. (2011). ¿Condicionan los recursos naturales el crecimiento económico? Semestre Económico- Universidad de Medellin, 117-128.

Amador, K. A. (2008). Tesis "La Ventaja Revelada de la Fresa Mexicana, su Estructura Productiva y Nivel de Protección en el Comercio Internacional". Morelia: ININEE; UMSNH.

Barrera, G., \& Sánchez, C. (2003). Caracterización de la Cadena Agroalimentaria/ Agroindustrial Nacional, Identificación de sus Demandas Tecnológicas: Fresa. Obtenido de INIFAP: file://C:/Users/Yo/Documents/ZAMORA/Lecturas/penit26.pdf

Cantú, A. G. (1995). Productividad y Reducción de Costos. Para la pequeña y mediana industria. México: Trillas.

CONAFRE, \& Comité de la Agroindustria y Productores, d. (2011). Plan Rector Nacional. Obtenido de http://dev.pue. itesm.mx/sagarpa/nacionales/EXP_CNSP_FRESA/PLAN\%20 RECTOR\%20QUE\%20CONTIENE\%20PROGRAMA\%20DE\%20 TRABAJ0\%202012/PR_CNSP_FRESA_2012.pdf

Cué, A. (2010). Economía Internacional. México: Grupo Editorial Patria.

Eyssautier, M. (2002). Metodología de la Investigación. México: Thomson Learning. 
FAOSTAT. (2013). Food and Agriculture Organization of the United Nations. Obtenido de http://faostat3.fao.org/ browse/I/IG/E

Fondo Sectorial de Investigación en Materia Agrícola, Pecuaria, Acuacultura, Agrobiotecnología y Recursos Fitogenéticos. (2012). SAGARPA; CONACYT; COFUPRO. Obtenido de http://conacyt.gob.mx/index.php/el-conacyt/ convocatorias-y-resultados-conacyt/convocatorias-fondossectoriales-constituidos/convocatoria-sagarpa-conacyt/ historicas-sagarpa/2012-03-sagarpa-conacyt/4049--515/ file

FSSC. (2016). Food Safety System Certification. Obtenido de http://fssc22000.com/sp/page.php

Global Standards. (18 de 05 de 2012). Agrana Fruits. Obtenido de https://www.youtube.com/watch?v=-8iD0DL-9Jo

González-Estrada, A., \& Gallegos-Cedillo, G. (2014). El producto interno bruto de los municipios M-Z. Revista Mexicana de Ciencias Agrícolas Vol. 5, 1410.

IMC0. (2010). Obtenido de Michoacán.Análisis de Competitividad 2010: http://imco.org.mx/indice_estatal_2010/PDFS/16. Michoacan.pdf

IMC0. (2016). Instituto Mexicano para la Competitividad A.C. Obtenido de http://www.competitividadinternacional.org/

INEGI. (2001). Manual para la Codificación de la Actividad Económica Involucrada de las Estadísticas sobre las Relaciones Laborales. Recuperado el 15 de 12 de 2015, de INEGI / SCIAN: http://www3.inegi.org.mx/rnm/index.php/ catalog/13/download/1817.

INEGI. (2010). Cuéntame: información por entidad. Obtenido de http://cuentame.inegi.org.mx/monografias/informacion/ gto/poblacion/m_migratorios.aspx?tema=me\&e $=11$

INEGI. (2014). PIB y Cuentas Nacionales. Obtenido de http:// www.inegi.org.mx/est/contenidos/proyectos/cn/pibe/

Jiménez, E. M. (2003). Nuevas Teorías y Enfoques Conceptuales sobre el Desarrollo Regional: ¿Hacia un Nuevo Paradigma? Revista de Economía Institucional, 38-39.
López, M. P. (2010). Las tres C's. Competencias, Competitividad y Conocimiento en el Desarrollo del talento humano. SINNCO, 5-6.

OIM. (2015). Organización Internacional para las Migraciones. Obtenido de Glosario de la OIM sobre la Migración: https:// www.iom.int/es/los-terminos-clave-de-migracion

Rangel, J. E. (2014). Flujos de comercio regional: Caso del Trans-Pacific Strategic Economic Partenership Agreement (TPP). (J. E. Rangel, Intérprete) Poliforum, Morelia, Michoacán, México.

SAGARPA. (2009). Oportunidades de mercado para Michoacán 2009. Obtenido de http://2006-2012.sagarpa.gob.mx/ agronegocios/Documents/ONMichoacan.pdf

SAGARPA. (05 de 2016). Obtenido de http://www.sagarpa. gob.mx/ProgramasSAGARPA/2016/Paginas/default.aspx

SEDEC0. (2012). Guía de Negocios Michoacán. Morelia: Gobierno del Estado.

SEDECO. (2014). Dossier. Michoacán Destino de Inversión. Handbook. Morelia, Michoacán, México: SEDECO.

SIAP. (2016). Servicio de Información Agroalimentaria y Pesquera. Obtenido de http://www.siap.gob.mx/ cierre-de-la-produccion-agricola-por-estado/

Toro, J. Á. (1985). Zamora antes del boom fresero. Relaciones, 39.

Unión Agrícola Regional de Productores de Fresa y Hortalizas del Valle de Zamora. (30 de 11 de 2009). SISTEMA PRODUCTO FRESA. Obtenido de ESTUDIO DE OPORTUNIDADES DE MERCADO E INTELIGENCIA COMERCIAL INTERNACIONAL PARA FRESA: http://www.sagarpa.gob.mx/agronegocios/ documents/estudios_promercado/fresa.pdf

Uribe, L. M. (2010). Consejo Nacional de Población. Obtenido de Índice de Intensidad Migratoria: http://www.conapo. gob.mx/work/models/CONAPO/intensidad_migratoria/pdf/ IIM_Estatal_y_Municipal.pdf 